\title{
Determining an Umbilical Cord pH Cutoff Value for Predicting Neonatal Morbidity Related to Intrapartum Hypoxia
}

\author{
MAGDALENA MOGOS, CATALIN GABRIEL HERGHELEGIU*, RALUCA GABRIELA IOAN, CRINGU ANTONIU IONESCU, \\ ADRIAN NEACSU \\ Carol Davila, University of Medicine and Pharmacy, 88 Mircea Vulcanescu, 010825, BUcharest, Romania
}

\begin{abstract}
Intrapartum hypoxia can lead to perinatal asphyxia, acidosis, neuronal injury, long-term morbidity or even death. Intrapartum asphyxia and hypoxia can be predicated by fetal acidosis. Umbilical cord gases are used to evaluate a newborn's acid-base status and the presence of hypoxia. Depending on what references are used, normal values for umbilical cord gases can wildly vary. Although most papers set a $\mathrm{pH}$ threshold of $<7.2$ for fetal acidosis / acidemia, some studies suggest that neonatal morbidity and mortality is increased only when the $\mathrm{pH}$ threshold is set below / cut-off value is 7.0. We did a retrospective study and evaluated all newborns from singleton term births in INSMC Alessandrescu Rusescu between 2010 - 2012. We found 83 cases of intrapartum asphyxia (IA) and 25 cases of hypoxic ischemic encephalopathy (HIE). Also a control group of 100 normal term newborns were randomly selected. The IA and HIE showed significant lower mean umbilical cord pH values compared to the control group (7.19, respectively 7.12 compared to 7.28). Using the Youden index we calculated $\mathrm{pH}$ a cutoff value of 7.25 for the prediction of IA and of 7.16 for the prediction of HIE. While a low Apgar score can be a predictor of neonatal outcome and may be determined byfetal hypoxia, it remains a subjective evaluation with variable intra-observer reliability. Thus it is important to have an objective test able to accurately diagnose perinatal asphyxia and predict the neonatal outcome.
\end{abstract}

Keywords: intrapartum asphyxia, hypoxic ischemic encephalopathy, umbilical cord gases

Intrapartum hypoxia can lead to perinatal asphyxia, acidosis, neuronal injury, long-term morbidityor even death [1-4]. An objective measurement of intrapartum hypoxia may predict those neonates at risk for morbidity and mortality $[5,6]$. Intrapartum asphyxia and hypoxia can be predicated by fetal acidosis [7-9].

The presence of hypoxia during labor results in fetal asphyxia that in turn, is characterized by fetal acidosis, depression of vital functions, long term morbidity and mortality [10]. Intrapartum hypoxia can have multiple causes starting with prematurity and distocic labor going to serious accidents such as retroplacental hematoma [11, 12]. Umbilical cord gases are used to evaluate a newborn's acid-base status and the presence of hypoxia in acute and chronic fetal distress various etiologies [13].

Umbilical cord $p \mathrm{H}$ is often used as an indicator if fetal oxygenation before birth and the Apgar score reflects newborn adaptation. Depending on what references are used, normal values for umbilical cord gases can wildly vary. Although most papers set a pH cut-off value of 7.2 for fetal acidosis / acidemia, some studies suggest that neonatal morbidity and mortality is increased only when the $\mathrm{pH}$ cut-off value is $7.0[6,7,14]$. On the other hand other studies suggest a higher $\mathrm{pH}$ cut-off value of 7.25 as being optimal for predicting neonatal morbidity [15]. Because there is no consensus as to what the threshold for $p H$ should be considered abnormal, there still uncertainty regarding the below what values should the $\mathrm{pH}$ be considered to be predictive for an unfavorable neonatal outcome.

We conducted a retrospective study to evaluate if umbilical cord blood $\mathrm{pH}$ can be a mean of predicting morbidity and mortality due to asphyxia, in term neonates.

\section{Experimental part \\ Method}

The study was retrospective and evaluated 10356 newborns that were registered between 2010 and 2012 in
INSMC Alessandrescu Rusescu, Bucharest, Romania. The information was collected form the archived patient medical record and included: gestation age, fetal heart rate monitoring during labor, birth weight, Apgar score, umbilical blood gases $(\mathrm{pH})$ performed on ABL800 FLEX blood gas analyzer, neonatal treatment and outcome.

All newborns from term singleton births with markers of a severe hypoxic event during labor defined as the presence of at least one of the following: severe changes in fetal heart rate $(<100,>160)$ or meconium staining and in the presence of at least one of the following: low Apgar score ( $\leq 3$ in the first minute or $\leq 5$ after five minutes); respiratory failure (defined/characterized as absence of spontaneous breathing after more than 5 min or mechanical ventilation for more than $10 \mathrm{~min}$ ); the need for intensive care unit admission for more than $24 \mathrm{~h}$; were included in the intrapartum asphyxia group (IA). Those with at least one of the following: hypotonia; seizures; hyperexcitability; depression of reflexes; subnormal level of consciousness; were included in the hypoxic ischemic encephalopathy (HIE) group.

The exclusion criteria for both IA and HIE groups were: encephalopathy determined by causes other than IA, congenital malformations, congenital metabolic diseases, viral infection, septic shock, major organ failure, fetal trauma during birth.

A control group of 100 healthy newborns from term singleton births, that did not meet any of the above criteria (IA, HIE, exclusion), and that had information regarding umbilical cord gases, was randomly selected from the 10356 newborn that were registered between 2010 and 2012.

Term pregnancy was defined as a gestational age of 37 weeks or greater.

Receiver operating characteristics (ROC) curves were constructed to assess the accuracy and predictive value of umbilical cord pH for IA and HIE [16]. To estimate the 


\begin{tabular}{|l|l|l|l|}
\hline Groups & Control $(n=100)$ & IA $(n=83)$ & HIE $(n=25)$ \\
\hline Umbilical cord $\mathrm{pH}$ & $7.28 \pm 0.06(7.13-7.37)$ & $7.19 \pm 0.07(7.09-7.32)$ & $7.12 \pm 0.03(7.09-7.20)$ \\
\hline
\end{tabular}

Table 1

THE $p H$ VALUES FOR THE CONTROL, IA AND HIE GROUPS

optimal $\mathrm{pH}$ cutoff value for diagnostic effectiveness, the maximal Youden index was used [17].

The data was collected using Office - Excel and the statistical analysis was made using NCSS 12 - Descriptive statistics; Two sample ttest; ROC curve and cutoff analysis.

\section{Results and discussions}

From the total of 10356 births that occurred between 2010 - 2012, we found 83 cases that met our criteria for $I A$, of which 25 cases also met our criteria for HIE.

The 83 cases of IA, presented increased morbidity, including: low Apgar score, respiratory failure, complications due to the mechanical ventilation, signs of neurological damage, infection. Out of the 25 cases of HIE there were 7 deaths, while in total there were 91 newborn deaths in the period 2010-2012. Thus there is a 28 fold increase in death rate in the HIE group, compared with the total mortality which in $1.1 \%$.

The umbilical cord $p \mathrm{H}$ was significantly lower in the IA and EHI groups, compared to the Control group as shown in table 1 and figure 1 . In the IA group $\mathrm{pH}$ values ranged between X-y with a mean of $7.19 \pm 0.07$, while in the EHI group the $p \mathrm{H}$ values ranged between 7.09-7.20 with a mean of $7.12 \pm 0.03$.

The ROC curves of $\mathrm{pH}$ for predicting $\mathrm{IA}$ and $\mathrm{EHI}$ are shown in figure 2 . Using the ROC curves we analyzed the predictive value for IA and EHI of different umbilical cord
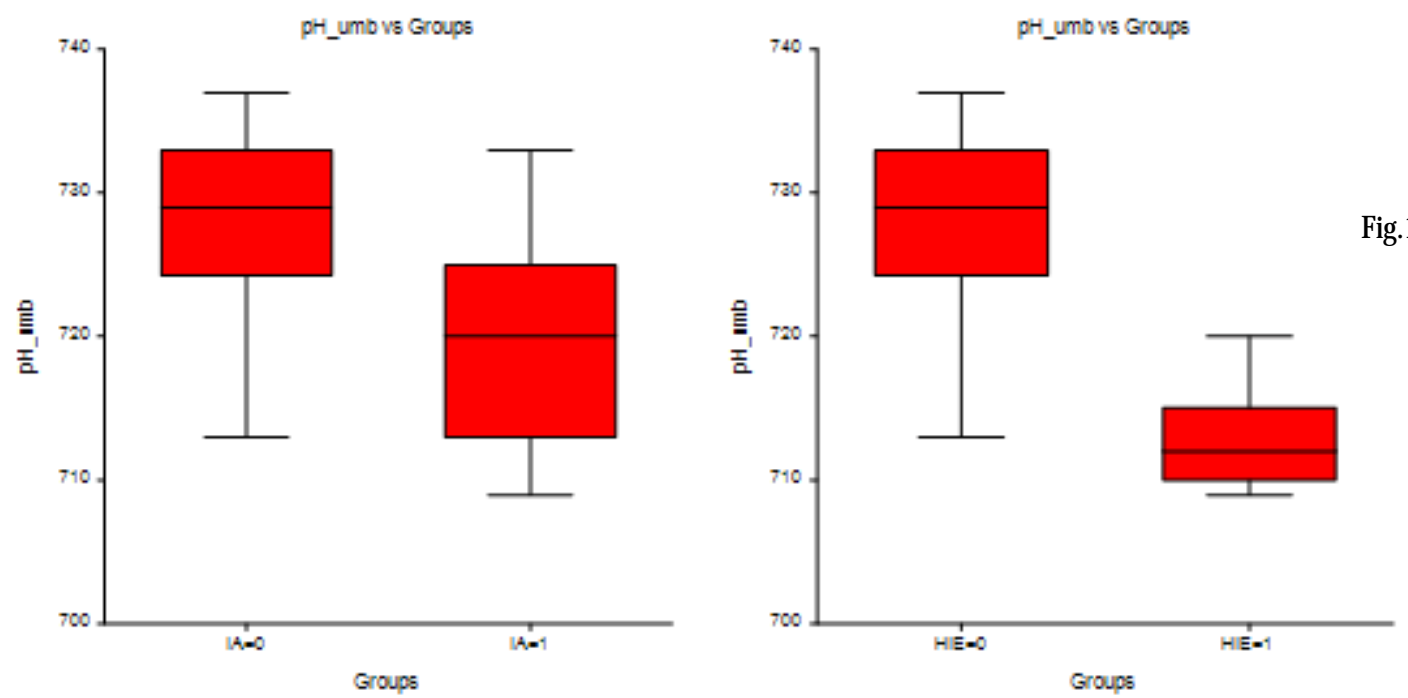

Fig.1. Box plots of Control, IA and EHI groups

\begin{tabular}{|l|l|l|l|l|}
\hline & \multicolumn{2}{|c|}{ IA Group } & \multicolumn{2}{c|}{ HIE Group } \\
\hline \multicolumn{1}{|c|}{ pH cutoff } & Sensitivity & Specificity & Sensitivity & Specificity \\
\hline$\leq 7.10$ & $9.6 \%$ & $100 \%$ & $28.0 \%$ & $99.3 \%$ \\
\hline $\begin{array}{l}\leq 7.12 \\
\text { (the } 10^{\text {th }} \text { percentile) }\end{array}$ & $22.9 \%$ & $100 \%$ & $60.0 \%$ & $97.5 \%$ \\
\hline $\begin{array}{l}\leq 7.16 \text { ("optimal" cutoff } \\
\text { for HIE from ROC curve) }\end{array}$ & $36.1 \%$ & $97 \%$ & $92.0 \%$ & $93.6 \%$ \\
\hline$\leq 7.20$ & $50.6 \%$ & $87.0 \%$ & $100 \%$ & $81.0 \%$ \\
\hline $\begin{array}{l}\leq 7.25 \text { ("optimal" cutoff } \\
\text { for IA from ROC curve) }\end{array}$ & $78.3 \%$ & $72 \%$ & $100 \%$ & $56.9 \%$ \\
\hline
\end{tabular}

Table 2

PREDICTIVE CHARACTERISTICS OF DIFFERENT $p H$ CUTOFFS FOR INTRAPARTUM ASPHYXIA AND HYPOXIC ISCHEMIC ENCEPHALOPATHY
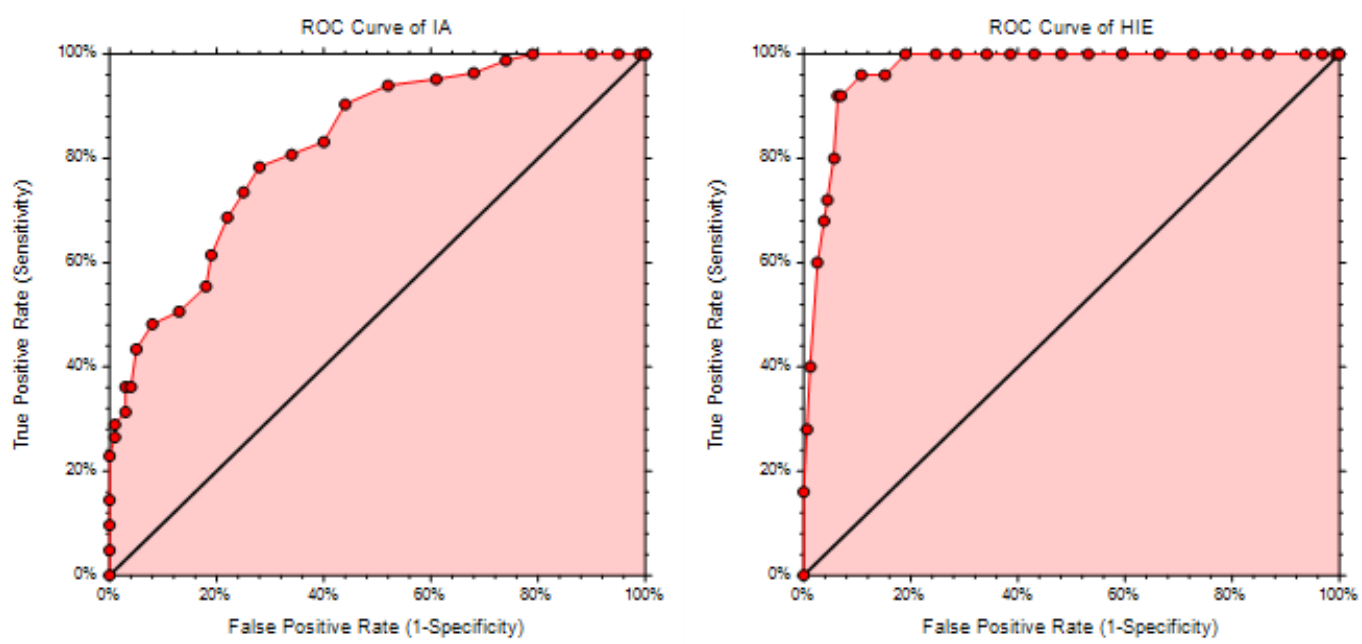

Fig. 2. ROC curves for IA and HIE 
$\mathrm{pH}$ cutoffs, the results are shown in table 2 . Based on the maximum calculated Youden index of 0.50 , for predicting $\mathrm{IA}$, the optimal cutoff value for $\mathrm{pH}$ was $\leq 7$. For the EHI group the maximum calculated Youden index was 0.85 , corresponding to an optimalcutoff value for the $\mathrm{pH}$ of $\leq 7.16$.

\section{Conclusions}

The study shows that low umbilical cord $p H$ has a strong and consistent association with perinatal asphyxia, morbidity and mortality, thus proving to be an important tool in evaluating the newborn. Also, the results prove that umbilical cord $\mathrm{pH}$ is useful in determining which newborns are likely to require further evaluation for the diagnosis of HIE.

While a low Apgar score can be a predictor of neonatal outcome and may be determined by fetal hypoxia, it remains a subjective evaluation with variable intraobserver reliability. Furthermore low Apgar scores have a very low positive predictive value for fetal acidemia and also on the other hand over $80 \%$ of newborns with acidemia have an Apgar score $>7$ [18]. Thus it is important to have an objective test able to accurately diagnose perinatal asphyxia and predict the neonatal outcome. We established that a cut-off value of 7.25 for the umbilical cord $\mathrm{pH}$ offers a good compromise between sensitivity and specificity in establishing perinatal asphyxia, offering the best diagnostic effectiveness. Furthermore, lowering the $\mathrm{pH}$ threshold even more, increases the specificity, thus a $\mathrm{pH} \leq 7.16$ offers a $90 \%$ positive predictive value for IA.

Our study confirms that although not all neonates with acidosis at birth develop neurological problems and HIE, the likelihood of poor outcome increases as the umbilical cord $\mathrm{pH}$ values are lower, finding that is also reported in other studies [19]. Using the Youden index, the optimal pH cutoff value for EHI was 7.16.

As many studies have shown it is difficult to establish what is the normal $\mathrm{pH}$ value, as various authors have suggested values ranging between 7.20 to 7.30 [20]. Furthermore some studies suggest that normal cord gases are not entirely incompatible with brain hypoxia, but this situation is very rare [19].

As in the prediction of premature labor, where we can not rely on a single biomarker [21] and here we can not rely entirely on umbilical cord $\mathrm{pH}$ to detect intrapartum asphyxia and prediction.

And last but not least, the tendencies to permanently monitoring fetal distress and other maternal-fetal parameters through the development of intelligent sensors and textiles [22, 23], as well as in our country, should be mentioned [24].

\section{References}

1.FATEMI, A.,WILSON, M.A., and JOHNSTON, M.V., Clinics in Perinatology, 36, nr. 4, 2009, p. 835-858.

2.SCHIFRIN, B.S., and ATER, S., Current Opinion in Obstetrics and Gynecology, 18, nr. 2, 2006, p. 112-122.
3.BOBROW, C. S., and SOOTHILL, P. W., Archives of Disease Childhood, 80, nr. 3, 1999, p. F246-F249.

4.OMO-AGHOJ A, L., Annals of Medical and Health Sciences Research, 4, nr. 1, 2014, p. 8-17.

5.RENNIE, J. M., HAGMANN, C. F. and ROBERTSON, N. J ., Seminars in Fetal \& Neonatal Medicine, 12, nr. 5, 2007, p. 398-407.

6.MALIN, G.L., MORRIS, R.K. and KAHN, K.S., British Medical Journal, 340, 2010, p. c1471.

7.FAHEY, J. and KING, T.L., Journal of Midwifery \& Womens Health, 50, nr. 6, 2005, p. 498-506.

8.VICTORY, R., PENAVA, D.,DA SILVA, O.,NATALE, R. and RICHARDSON, B., American Journal of Obstetrics and Gynecology, 191, nr. 6, 2004, p. 2021-2028.

9.ROSS, M.G. and GALA, R., American J ournal of Obstetrics and Gynecology, 187, nr. 1, 2002, p. 1-9.

10.HAMED, H.O., Archives of Gynecology and Obstetrics, 287, nr. 6, 2013, p. 1067-1073.

11. BRAILA, A.D., GLUHOVSCHI, A., NEACSU, A., LUNGULESCU, C.V., BRAILA, M., VîRCAN, E.L., COTOI, B.V., GOGANAU, A.M., RJ ME, 59, nr. 1, 2018, p. 187-195.

12. BRAILA, A.D., KRASTEV , M.B., MIHAI-ZAMFIR, E., CARAVETEANU, D.C., AL KRAYEM, N., BRAILA, M., VELEA, R., NEACSU, A., RJME, 58, nr. 4, 2017, p. 1465-1470.

13. BRAILA, A.D., NEACSU, A., MUSETESCU, A.E., VIRCAN, E.L., FLORESCU, A., BUMBEA, A.M., Rev. Chim. (Bucharest), 69, no.8, 2018, p. 2300-2303.

14.INGEMARSSON, I., HERBST, A. and THORNGREN, K., British

J ournal of Obstetrics and Gynaecology, 104, nr. 10, 1997, p. 1123-1127. 15.TUULI, M.G., STOUT, M. J., SHANKS, A., ODIBO, A.O., MACONES, G.A. and CAHILL, A.G., Obstetrics and. Gynecology, 124, nr. 4, 2014, p. 756-761.

16.ZWEIG, M.H. and CAMPBELL, G., Clinical Chemistry, 39, nr. 4, 1993, p. 561-577.

17.YOUDEN, W.J., Cancer, 3, nr. 1, 1950, p. 32-35.

18.DEPP, R., Seminars in Pediatrics Neurology, 2, nr. 1, 1995, p. 3-36. 19.YEH, P., EMARY, K. and IMPEY, L., BJ OG An International J ournal of Obstetrics and Gynaecology, 119, nr. 7, 2012, p. 824-831.

20.HELWIG, J.T., PARER, J.T., KILPATRICK, S.J. and LAROS, R.K., American Journal of Obstetrics and Gynecology, 174, nr. 6, 1996, p. 1807-1814.

21.NEACSU, A., CALIN, A., BRAILA, A.D., NAVOLAN, D., DIMITRIU, M., STANICA, C.D., IOAN, R., IONESCU, C.A., Re. Chim. (Buchares), 69, no. 7, 2018, p. 1796-1801.

22.BOUGIA, P., KAIRVOUNIS, E., FOTIADIS, D. I.,Chapter 10 - Smart medical textiles for monitoring pregnancy. In : Van Langenhove $L$ (eds) . Smart textiles for medicine and healthcare : Materials, systems and applications, Woodhead Publishing Limited, Cambridge, England, 2007 , p. 183-204

23.CHEN, W., HU, J., BOUWSTRA, S., OETOMO, S. B., FEIJS, L., International J ournal of Sensors Networks, 9, nr.1, 2011, p. 38-49.

24.ONOSE, G., CHENDREANU, C., NEACSU, A., GRIGOREAN, V., STRAMBU, V., TOADER, C., SPANU, A., ANDONE, I., ANGHELESCU, A., ONOSE, L., HARAS, M., SINESCU, C. J., ARTINO, M., CIORNEI, C., MIREA, A., Industria Textila, 60, nr. 3, 2009, p. 124-133.

Manuscript received: 6.10 .2108 